\title{
An Elastic-Viscous-Plastic Sea Ice Model formulated on Arakawa B and C Grids
}

\author{
Sylvain Bouillon ${ }^{a, c, 1}$,Miguel Ángel Morales Maqueda ${ }^{b}$ \\ Vincent Legat ${ }^{c}$ and Thierry Fichefet ${ }^{a}$ \\ ${ }^{a}$ G. Lemaître Institute of Astronomy and Geophysics (ASTR), \\ Université catholique de Louvain, 2 Chemin du Cyclotron, B-1348 \\ Louvain-la-Neuve, Belgium. \\ ${ }^{b}$ Proudman Oceanographic Laboratory (POL), \\ 6 Brownlow Street, Liverpool L3 5DA, United Kingdom. \\ ${ }^{c}$ Center for Systems Engineering and Applied Mechanics (CESAME), \\ Université catholique de Louvain, 4 Avenue G. Lemaître, B-1348 \\ Louvain-la-Neuve, Belgium.
}

Key words: Sea ice, Coupled sea ice-ocean model, Elastic-viscous-plastic rheology, Model grid

\section{Introduction}

The dynamic component of most sea ice models designed for climate studies is based on the ice momentum balance formulation of Hibler (1979). In this model, sea ice is assumed to be a non-linear viscous-plastic (VP) material whose resistance to deformation depends on its instantaneous state of motion and several large-scale scalar properties, such as ice thickness and lead fractional area. The VP formulation of Hibler (1979) has known many successes, but it is computationally expensive and not well suited for efficient parallel integrations. The numerical method first used to solve the VP dynamics was a relatively slow implicit point relaxation method (Hibler, 1979). More efficient implicit methods have been proposed subsequently, namely, the line relaxation method (Zhang and Hibler, 1997) and the alternating direction implicit method (Zhang and Rothrock, 2000). However, the most popular alternative for the calculation of the VP dynamics is the elastic-viscous-plastic (EVP) formulation of Hunke and Dukowicz (1997). Distinctive advantages of the EVP

$\overline{1}$ Corresponding author. E-mail: sylvain.bouillon@uclouvain.be, Tel: +32104730 67, Fax: +32 10474722 
dynamics over the VP dynamics is that it is much simpler to program and can be solved explicitly in time, thus easing parallelization.

Because of the appealing numerical properties of the EVP dynamics, a growing number of large-scale, coupled ocean-sea ice and atmosphere-ocean-sea ice models have adopted this formulation (e.g., Randall et al., 2007). Prompted by this trend, we have incorporated the EVP rheology in the Louvain-la-Neuve sea-Ice Model, LIM (Fichefet and Morales Maqueda, 1997, 1999). LIM is the default sea ice module of the Nucleus for European Modelling of the Ocean (NEMO, http://www.locean-ipsl.upmc.fr/NEMO/). LIM is also widely used outside the NEMO project. It is the sea ice component of the global coupled sea ice-ocean model CLIO (Goosse and Fichefet, 1999), and has been coupled to the ocean general circulation models OPA (Océan PArallélisé), which is the precursor of NEMO (Madec et al., 1999), and MOM3 (Modular Ocean Model, version 3, Hofmann and Morales Maqueda (2006)), as well as to Earth system models of intermediate complexity CLIMBER3 $\alpha$ (Montoya et al., 2005) and LOVECLIM (Driesschaert et al., 2007), and to the climate general circulation model IPSL-CM4 (Marti et al., 2008). Simulations with the coupled OPALIM model have been analyzed by Timmermann et al. (2005), and a new version of the model including an arbitrary number of ice thickness categories and a multi-layer halo-thermodynamic module has been recently completed by Vancoppenolle et al. (2008).

Official releases of LIM have, until now, employed the VP dynamics formulation, although a cavitating fluid approach was also briefly tested by Fichefet and Morales Maqueda (1997), and the versions of LIM coupled to MOM3 and CLIMBER3 $\alpha$ do incorporate already implementations of the EVP dynamics. However, this work is the first attempt to evaluate the impact of the EVP parameterization on LIM.

We have tested three versions of the EVP dynamics in LIM, namely, the most recent bilinear discretization of Hunke and Dukowicz (2002) on an Arakawa B grid, and two simpler discretizations that we will describe here in full, the first of which is also formulated on a $\mathrm{B}$ grid, while the second is for a $\mathrm{C}$ grid. We present results of simulations with the coupled OPA-LIM model, each employing one of the three EVP formulations that we have just referred to. For comparison, a fourth integration was also carried out with the original VP parameterization. Reassuringly, all three EVP discretizations produce very similar results. However, the $\mathrm{C}$ grid version is the one that has been chosen for use within the NEMO project, as it is faster than any of the other two and affords a more direct coupling with the ocean component of NEMO, which is an updated version of OPA and is also discretized on a $\mathrm{C}$ grid.

The article is organized as follows. Section 2 succinctly describes LIM. Section 3 discusses issues pertaining to the new discretization of the model dynamics, 
specially as regards the new implementation on a $\mathrm{C}$ grid. Section 4 presents an intercomparison of key results from the numerical simulations. Conclusions are presented in Section 5.

\section{Model description}

The version of LIM used in this study (LIM2) is described in full detail in Timmermann et al. (2005) and references therein. Therefore, only a brief summary of the model, with emphasis on its dynamics, is given here.

The thermodynamic part of LIM (Fichefet and Morales Maqueda, 1997, 1999) uses a three-layer model for the vertical heat conduction within snow and ice. The storage of latent heat in brine pockets is taken into account, and sea ice growth and decay rates are obtained from the ice energy budget. Airice and air-ocean heat fluxes are computed using empirical parameterizations described by Goosse (1997), and the ice-ocean heat flux is computed as in McPhee (1992).

The model dynamics are based on the two-category (consolidated ice plus leads) approach of Hibler (1979). This two-category ice cover is treated as a two-dimensional compressible fluid driven by winds and oceanic currents. Sea ice resist deformation with a strength which increases monotonically with ice thickness and concentration.

The conservation of linear momentum for sea ice is expressed as in Leppäranta (2005) by

$$
m \boldsymbol{u}_{t}=\boldsymbol{\nabla} \cdot \boldsymbol{\sigma}+A\left(\boldsymbol{\tau}_{a}+\boldsymbol{\tau}_{w}\right)-m f \boldsymbol{k} \times \boldsymbol{u}-m g \boldsymbol{\nabla} \eta
$$

where $m$ is the ice mass per unit area, $\boldsymbol{u}$ is the ice velocity, $\boldsymbol{\sigma}$ is the internal stress tensor, $A$ is the ice area fraction, or concentration, $\boldsymbol{\tau}_{a}$ is the wind stress, $\boldsymbol{\tau}_{w}$ is the ocean stress (typically quadratic), $f$ is the Coriolis parameter, $\boldsymbol{k}$ is an upward pointing unit vector, $g$ is the gravity acceleration and $\eta$ is the ocean surface elevation with respect to zero sea level. Note that the momentum advection is being ignored in (1) and that the wind and ocean stresses are multiplied by the ice concentration as suggested by Connolley et al. (2004).

Calculation of sea ice internal forces in LIM has customarily been done using the VP approach of Hibler (1979), which, in practice, is a particular case of the EVP formulation of Hunke and Dukowicz (1997). A description of the general framework for the VP and EVP formulations of the ice internal stresses is given in Hunke and Dukowicz (2002) and Hunke and Lipscomb (2006). For completion, we reproduce here the key elements of such a framework. Let us 
denote $\sigma_{11}, \sigma_{22}$ and $\sigma_{12}$ the components of the ice internal stress tensor, and let

$$
\begin{aligned}
\sigma_{1} & =\sigma_{11}+\sigma_{22}, \\
\sigma_{2} & =\sigma_{11}-\sigma_{22}, \\
D_{D} & =\frac{1}{h_{1} h_{2}}\left(\frac{\partial}{\partial \xi_{1}}\left(h_{2} u\right)+\frac{\partial}{\partial \xi_{2}}\left(h_{1} v\right)\right), \\
D_{T} & =\frac{1}{h_{1} h_{2}}\left(h_{2}^{2} \frac{\partial}{\partial \xi_{1}}\left(u / h_{2}\right)-h_{1}^{2} \frac{\partial}{\partial \xi_{2}}\left(v / h_{1}\right)\right), \\
D_{S} & =\frac{1}{h_{1} h_{2}}\left(h_{1}^{2} \frac{\partial}{\partial \xi_{2}}\left(u / h_{1}\right)+h_{2}^{2} \frac{\partial}{\partial \xi_{1}}\left(v / h_{2}\right)\right),
\end{aligned}
$$

where $D_{D}, D_{T}$ and $D_{S}$ are the divergence, horizontal tension and shearing strain rates, respectively, $\xi_{1}$ and $\xi_{2}$ are generalized orthogonal coordinates, and $h_{1}$ and $h_{2}$ are the associated scale factors. With these definitions, the stress tensor is given by

$$
\begin{aligned}
\sigma_{1} & =\left(\frac{D_{D}}{\Delta}-1\right) P, \\
\sigma_{2} & =\frac{D_{T}}{e^{2} \Delta} P, \\
\sigma_{12} & =\frac{D_{S}}{2 e^{2} \Delta} P,
\end{aligned}
$$

where $P$ is the ice compressive strength, $e$ is the the ratio of principal axes of the elliptical yield curve (see below) and $\Delta$, a measure of the deformation rate, is given by

$$
\Delta=\sqrt{D_{D}^{2}+\frac{1}{e^{2}}\left(D_{T}^{2}+D_{S}^{2}\right)} .
$$

Note that the tensor given by (7) to (9) is entirely equivalent to the more classic Reiner-Rivlin formulation used by Hibler (1979).

This rheology links the compressive stress, $\sigma_{1}$, to the shearing stress, $\sigma_{s}=$ $\sqrt{\sigma_{2}^{2}+4 \sigma_{12}^{2}}$, by the following quadratic relation,

$$
\left(\sigma_{1} / P+1\right)^{2}+e^{2}\left(\sigma_{s} / P\right)^{2}=1
$$

which defines an elliptical yield curve. The ice compressive strength $P$ is empirically related to the ice thickness per unit area, $h$, and ice concentration, $A$, by $P=P^{*} h e^{-C(1-A)}$, where $P^{*}$ and $C$ are empirical constants.

In (7)-(9), a regularization is needed when $\Delta$ goes to zero. A simple regularization is to set a lower bound, $\Delta_{m i n}$, for $\Delta$. For values of $\Delta$ smaller than $\Delta_{m i n}$, sea ice behaves like a linear viscous fluid undergoing very slow creep. As we shall see below, if the plastic behavior of sea ice is to be accurately represented, $\Delta_{\min }$ 
must be sufficiently small (say $10^{-9} \mathrm{~s}^{-1}$ or less). Note that $\Delta_{\min }$ is directly related to the $\zeta_{\max }$ parameter used in Hibler (1979) by $\zeta_{\max }=P /\left(2 \Delta_{\min }\right)$.

An alternative regularization was proposed by Hunke and Dukowicz (1997), and it consists in introducing time dependence and an artificial elastic term in (7)-(9), leading to the EVP formulation:

$$
\begin{aligned}
2 T \sigma_{1, t}+\sigma_{1} & =\left(\frac{D_{D}}{\Delta}-1\right) P, \\
\frac{2 T}{e^{2}} \sigma_{2, t}+\sigma_{2} & =\frac{D_{T}}{e^{2} \Delta} P, \\
\frac{2 T}{e^{2}} \sigma_{12, t}+\sigma_{12} & =\frac{D_{S}}{2 e^{2} \Delta} P,
\end{aligned}
$$

where $T$ is a time scale that controls the rate of damping of elastic waves. Note that, while (12)-(14) become (7)-(9) in the steady state, static flow in the EVP rheology is represented by an elastic deformation, and so imposing a minimum value of $\Delta$ is no longer necessary. Hunke and Dukowicz (1997) showed that the numerical solution of (1) in combination with (12)-(14) does indeed converge to the VP stationary solution as long as the elastic time scale $T$ is several times smaller than the time scale of variation of the external forcing.

The components of the internal stress force are (Hunke and Dukowicz, 2002):

$$
\begin{aligned}
& 2 F_{1}=\frac{1}{h_{1}} \frac{\partial \sigma_{1}}{\partial \xi_{1}}+\frac{1}{h_{1} h_{2}^{2}} \frac{\partial\left(h_{2}^{2} \sigma_{2}\right)}{\partial \xi_{1}}+\frac{2}{h_{1}^{2} h_{2}} \frac{\partial\left(h_{1}^{2} \sigma_{12}\right)}{\partial \xi_{2}}, \\
& 2 F_{2}=\frac{1}{h_{2}} \frac{\partial \sigma_{1}}{\partial \xi_{2}}-\frac{1}{h_{1}^{2} h_{2}} \frac{\partial\left(h_{1}^{2} \sigma_{2}\right)}{\partial \xi_{2}}+\frac{2}{h_{1} h_{2}^{2}} \frac{\partial\left(h_{2}^{2} \sigma_{12}\right)}{\partial \xi_{1}} .
\end{aligned}
$$

\section{Discretizations of the model dynamics}

Numerical stability analyses show that explicit time integration of the VP dynamics would be very expensive. Indeed, the critical time step for a stable explicit VP scheme is about $1 \mathrm{~s}$ for a 100-km grid, and scales as $d^{2}$, where $d$ is the horizontal resolution (Hunke and Dukowicz, 1997). Given such a prohibitively small explicit time step, an implicit method of integration is required. In LIM, the implicit VP solver currently used closely follows the successive relaxation method of Hibler (1979) with under-relaxation. For typical spatial resolutions of $50 \mathrm{~km}$ to $100 \mathrm{~km}$, daily wind forcing variability and time step, $\Delta t$, of half a day to a quarter of a day, a few hundred iterations per time step are required for the relaxation scheme to converge. A type of predictor-corrector scheme is used for the ice dynamics, whereby, starting from a solution at time $t$, an intermediate solution is first evaluated at time $t+\Delta t / 2$. The solution at time $t+\Delta t$ is then calculated with the non-linear terms in the internal stress and 
ice-ocean stress terms centred at $t+\Delta t / 2$. For time steps of between 1 day and a few hours, the solution thus obtained may be a rather crude approximation of the real plastic flow, and the resulting stress state is likely to lie away from the yield curve. Accuracy can be improved by repeating the predictor-corrector calculation several times, say $n$, with a subcycling time step $\Delta t / n$.

In contrast to the VP dynamics, the EVP dynamics can be solved explicitly with time steps that can be few orders of magnitude larger than the maximum permissible explicit time step for the VP formulation. In addition, this maximum time step scales linearly, rather than quadratically, with $d$, although it also depends on the time scale $T$ (Hunke and Dukowicz, 1997; Hunke and Lipscomb, 2006). The explicit numerical solution of the EVP equations is thus significantly less expensive than implicit methods for the VP formulation. Moreover, the convergence of the calculated stress state toward the elliptic yield curve is relatively fast because all the non linear terms in (1) are reevaluated every time step. The EVP scheme is also easy to parallelize, and gives a higher speedup factor (measured as the ratio between wall clock serial time and wall clock parallel time) than parallel implementations of the VP method (Hunke and Zhang, 1999).

\subsection{B grid discretization}

We have introduced three discretizations of the EVP dynamics in LIM. The first discretization is the one formulated by Hunke and Dukowicz (2002). These authors use a sophisticated variational method to calculate the internal stress force in discrete generalized orthogonal curvilinear coordinates. Formally working on a B grid, and using bilinear approximations for the ice velocities over a given grid cell, the components of the strain rate and internal stress tensors are computed at the corners of each grid cell, thus requiring four computations per tensor component per grid cell. As Hunke and Dukowicz (2002) emphasize, this approach greatly helps to mitigate checkerboard mode solutions that are frequently generated on the B grid.

The discretization of Hunke and Dukowicz (2002) is computationally expensive because it requires four calculations of each component of the strain rate and internal stress tensors per grid cell. As an alternative, we have also implemented in LIM a naïve, centred difference discretization on the B grid. This second discretization is constructed as follows. On the B grid, consider a grid cell whose central, or scalar, point has indexes $i, j$. As shown in Fig. 1, the indexes of the four corners, or velocity points, of the cell are then $i-1 / 2, j-1 / 2$ (left, bottom corner), $i+1 / 2, j-1 / 2$ (right, bottom corner), $i+1 / 2, j+1 / 2$ (right, top corner), and $i-1 / 2, j+1 / 2$ (left, top corner). Analogously, the indexes of the four mid points on the grid cell sides, or transport points, are 
$i-1 / 2, j$ (left, centre point), $i, j-1 / 2$ (centre, bottom point), $i+1 / 2, j$ (right, centre point), and $i, j+1 / 2$ (centre, top point). Denoting the grid elements $e_{1}=h_{1} \Delta \xi_{1}$ and $e_{2}=h_{2} \Delta \xi_{2}$, where $\Delta \xi_{1}$ and $\Delta \xi_{2}$ are the spatial steps in the two orthogonal directions, the components of the strain rate tensor are given by

$$
\begin{aligned}
& 2 e_{1 i, j} e_{2 i, j} D_{D i, j}= \\
& e_{2 i+1 / 2, j}\left(u_{i+1 / 2, j+1 / 2}+u_{i+1 / 2, j-1 / 2}\right)-e_{2 i-1 / 2, j}\left(u_{i-1 / 2, j+1 / 2}+u_{i-1 / 2, j-1 / 2}\right)+ \\
& e_{1 i, j+1 / 2}\left(v_{i+1 / 2, j+1 / 2}+v_{i-1 / 2, j+1 / 2}\right)-e_{1 i, j-1 / 2}\left(v_{i+1 / 2, j-1 / 2}+v_{i-1 / 2, j-1 / 2}\right),
\end{aligned}
$$

$$
\begin{aligned}
& 2 e_{1 i, j} e_{2 i, j} D_{T i, j}= \\
& e_{2 i, j}^{2}\left(\frac{u_{i+1 / 2, j+1 / 2}+u_{i+1 / 2, j-1 / 2}}{e_{2 i+1 / 2, j}}-\frac{u_{i-1 / 2, j+1 / 2}+u_{i-1 / 2, j-1 / 2}}{e_{2 i-1 / 2, j}}\right)- \\
& e_{1 i, j}^{2}\left(\frac{v_{i+1 / 2, j+1 / 2}+v_{i-1 / 2, j+1 / 2}}{e_{1 i, j+1 / 2}}-\frac{v_{i+1 / 2, j-1 / 2}+v_{i-1 / 2, j-1 / 2}}{e_{1 i, j-1 / 2}}\right),
\end{aligned}
$$

$$
\begin{aligned}
& 2 e_{1 i, j} e_{2 i, j} D_{S i, j}= \\
& e_{1, j}^{2}\left(\frac{u_{i+1 / 2, j+1 / 2}+u_{i-1 / 2, j+1 / 2}}{e_{1 i, j+1 / 2}}-\frac{u_{i+1 / 2, j-1 / 2}+u_{i-1 / 2, j-1 / 2}}{e_{1 i, j-1 / 2}}\right)+ \\
& e_{2 i, j}^{2}\left(\frac{v_{i+1 / 2, j+1 / 2}+v_{i+1 / 2, j-1 / 2}}{e_{2 i+1 / 2, j}}-\frac{v_{i-1 / 2, j+1 / 2}+v_{i-1 / 2, j-1 / 2}}{e_{2 i-1 / 2, j}}\right) .
\end{aligned}
$$

All three quantities $D_{D i, j}, D_{T i, j}$ and $D_{S i, j}$ are defined on the centre of the grid cells. The components of the internal stress tensor, also defined on the grid cell centres, can now be evaluated by solving (12), (13) and (14). The internal stress force components, $F_{1}$ and $F_{2}$, which are defined on the grid cell corners, can then be calculated as

$$
\begin{aligned}
& 4 e_{1 i+1 / 2, j+1 / 2} e_{2 i+1 / 2, j+1 / 2} F_{1 i+1 / 2, j+1 / 2}= \\
& e_{2 i+1 / 2, j+1 / 2}\left(\sigma_{1 i+1, j+1}+\sigma_{1 i+1, j}-\sigma_{1 i, j+1}-\sigma_{1 i, j}\right)+ \\
& \frac{1}{e_{2 i+1 / 2, j+1 / 2}}\left(e_{2 i+1, j+1 / 2}^{2}\left(\sigma_{2 i+1, j+1}+\sigma_{2 i+1, j}\right)-e_{2 i, j+1 / 2}^{2}\left(\sigma_{2 i, j+1}+\sigma_{2 i, j}\right)\right)+ \\
& \frac{2}{e_{1 i+1 / 2, j+1 / 2}}\left(e_{1 i+1 / 2, j+1}^{2}\left(\sigma_{12 i+1, j+1}+\sigma_{12 i, j+1}\right)-e_{1 i+1 / 2, j}^{2}\left(\sigma_{12 i+1, j}+\sigma_{12 i, j}\right)\right) .
\end{aligned}
$$




$$
\begin{aligned}
& 4 e_{1 i+1 / 2, j+1 / 2} e_{2 i+1 / 2, j+1 / 2} F_{2 i+1 / 2, j+1 / 2}= \\
& e_{1 i+1 / 2, j+1 / 2}\left(\sigma_{1 i+1, j+1}+\sigma_{1 i, j+1}-\sigma_{1 i+1, j}-\sigma_{1 i, j}\right)- \\
& \frac{1}{e_{1 i+1 / 2, j+1 / 2}}\left(e_{1 i+1 / 2, j+1}^{2}\left(\sigma_{2 i+1, j+1}+\sigma_{2 i, j+1}\right)-e_{1 i+1 / 2, j}^{2}\left(\sigma_{2 i+1, j}+\sigma_{2 i, j}\right)\right)+ \\
& \frac{2}{e_{2 i+1 / 2, j+1 / 2}}\left(e_{2 i+1, j+1 / 2}^{2}\left(\sigma_{12 i+1, j+1}+\sigma_{12 i+1, j}\right)-e_{2 i, j+1 / 2}^{2}\left(\sigma_{12 i, j+1}+\sigma_{12 i, j}\right)\right) .
\end{aligned}
$$

The discretization in time of both the bilinear and centred difference formulations on the B grid follows that of Hunke and Lipscomb (2006), and is

$$
\begin{aligned}
2 T \frac{\sigma_{1}^{k+1}-\sigma_{1}{ }^{k}}{\Delta t}+\sigma_{1}{ }^{k+1} & =\left(\frac{D_{D}^{k}}{\Delta^{k}}-1\right) P, \\
\frac{2 T}{e^{2}} \frac{\sigma_{2}^{k+1}-\sigma_{2}{ }^{k}}{\Delta t}+\sigma_{2}^{k+1} & =\frac{D_{T}^{k}}{e^{2} \Delta^{k}} P, \\
\frac{2 T}{e^{2}} \frac{\sigma_{12}^{k+1}-\sigma_{12}{ }^{k}}{\Delta t}+\sigma_{12}^{k+1} & =\frac{D_{S}^{k}}{2 e^{2} \Delta^{k}} P,
\end{aligned}
$$

$$
\begin{aligned}
& m \frac{u^{k+1}-u^{k}}{\Delta t}= \\
& F_{1}^{k+1}+A\left(\tau_{a 1}+c_{D} \rho_{o}\left|\boldsymbol{u}_{o}-\boldsymbol{u}^{k}\right|\left(u_{o}-u^{k+1}\right)\right)+m f v^{k+1}-m g \frac{1}{h_{1}} \frac{\partial \eta}{\partial \xi_{1}} \\
& m \frac{v^{k+1}-v^{k}}{\Delta t}= \\
& F_{2}{ }^{k+1}+A\left(\tau_{a 2}+c_{D} \rho_{o}\left|\boldsymbol{u}_{o}-\boldsymbol{u}^{k}\right|\left(v_{o}-v^{k+1}\right)\right)-m f u^{k+1}-m g \frac{1}{h_{2}} \frac{\partial \eta}{\partial \xi_{2}}
\end{aligned}
$$

where, for expediency, we have dropped spatial sub-indexes, the super-indexes $k$ and $k+1$ denote variables evaluated at times $k \Delta t$ and $(k+1) \Delta t$, respectively, where $\Delta t$ is the dynamics time step, $c_{D}$ is the ice-ocean drag coefficient, $\rho_{o}$ is the reference density of seawater and $\boldsymbol{u}_{o} \equiv\left(u_{o}, v_{o}\right)$ is the surface oceanic current. The ice compressive strength $P$ is updated only every thermodynamics and ice transport time step, which is normally orders of magnitude larger than $\Delta t$.

\subsection{C grid discretization}

For each sea ice-ocean coupling step, the B grid discretization requires interpolation of sea ice fields onto the ocean grid, which is of Arakawa C type, and, likewise, surface oceanic fields need also to be interpolated onto the sea 
ice grid. Within the sea ice model, interpolation of sea ice drift rates onto the midpoint of grid cell sides is also required before transport of sea ice scalars is calculated. Such interpolations would be avoided if a $\mathrm{C}$ grid were used in the calculation of the sea ice dynamics, which is why we have also formulated a centred difference version of the EVP dynamics (see Kantha and Clayson (2000) for a C grid, centred difference formulation of the VP case). Another important reason why a $\mathrm{C}$ grid is desirable is that, with no slip boundary conditions, transport of scalar properties through narrow straits and passages with a width of just one single grid cell is possible on a $\mathrm{C}$ grid, while it is precluded on a B grid.

Using the same indexing conventions as for the B grid, the discretization of the strain rate tensor is

$$
\begin{aligned}
& e_{1 i, j} e_{2 i, j} D_{D i, j}= \\
& e_{2 i+1 / 2, j} u_{i+1 / 2, j}-e_{2 i-1 / 2, j} u_{i-1 / 2, j}+e_{1 i, j+1 / 2} v_{i, j+1 / 2}-e_{1 i, j-1 / 2} v_{i, j-1 / 2}, \quad(27) \\
& e_{1 i, j} e_{2 i, j} D_{T i, j}=e_{2 i, j}^{2}\left(\frac{u_{i+1 / 2, j}}{e_{2 i+1 / 2, j}}-\frac{u_{i-1 / 2, j}}{e_{2 i-1 / 2, j}}\right)-e_{1 i, j}^{2}\left(\frac{v_{i, j+1 / 2}}{e_{1 i, j+1 / 2}}-\frac{v_{i, j-1 / 2}}{e_{1 i, j-1 / 2}}\right), \\
& e_{1 i+1 / 2, j+1 / 2} e_{2 i+1 / 2, j+1 / 2} D_{S i+1 / 2, j+1 / 2}= \\
& e_{1 i+1 / 2, j+1 / 2}^{2}\left(\frac{u_{i+1 / 2, j+1}}{e_{1 i+1 / 2, j+1}}-\frac{u_{i+1 / 2, j}}{e_{1 i+1 / 2, j}}\right)+e_{2 i+1 / 2, j+1 / 2}^{2}\left(\frac{v_{i+1, j+1 / 2}}{e_{2 i+1, j+1 / 2}}-\frac{v_{i, j+1 / 2}}{e_{2 i, j+1 / 2}}\right) .
\end{aligned}
$$

Note that the components $D_{D}, D_{T}, \sigma_{1}$ and $\sigma_{2}$ are all defined on the cell centres, while $D_{S}$ and $\sigma_{12}$ are defined on the corners. The internal stress force component $F_{1}$ is located on $u$ points and $F_{2}$ on $v$ points. In a $\mathrm{C}$ grid, the velocity components are ideally located for the calculation of the components of the strain rate and the internal stress tensors, requiring fewer interpolations than on the $\mathrm{B}$ grid. As the invariant $\Delta$ is used to compute the internal stress components, it needs, however, to be computed both on cell centres and corners, and so, for the purpose of the calculation of $\Delta, D_{D}$ and $D_{T}$ must be interpolated onto cell corners, while $D_{S}$ must be interpolated onto cell centres. The expression for $D_{D}$ on cell corners is

$$
\begin{aligned}
& \left(e_{1 i, j+1 / 2}+e_{1 i+1, j+1 / 2}\right)\left(e_{2 i+1 / 2, j}+e_{2 i+1 / 2, j+1}\right) D_{D i+1 / 2, j+1 / 2}= \\
& e_{2 i+1 / 2, j+1}\left(e_{1 i+1, j+1 / 2} D_{D i, j}+e_{1 i, j+1 / 2} D_{D i+1, j}\right)+ \\
& e_{2 i+1 / 2, j}\left(e_{1 i+1, j+1 / 2} D_{D i, j+1}+e_{1 i, j+1 / 2} D_{D i+1, j+1}\right)
\end{aligned}
$$

with an analogous formula for $D_{T i+1 / 2, j+1 / 2}$, while the centred value of $D_{S}$ is 
given by

$$
4 D_{S i, j}=D_{S i-1 / 2, j-1 / 2}+D_{S i+1 / 2, j-1 / 2}+D_{S i+1 / 2, j+1 / 2}+D_{S i-1 / 2, j+1 / 2} .
$$

The internal stress force components on the $\mathrm{C}$ grid are

$$
\begin{aligned}
& 2 e_{1 i+1 / 2, j} e_{2 i+1 / 2, j} F_{1 i+1 / 2, j}= \\
& e_{2 i+1 / 2, j}\left(\sigma_{1 i+1, j}-\sigma_{1 i, j}\right)+\frac{1}{e_{2 i+1 / 2, j}}\left(e_{2 i+1, j}^{2} \sigma_{2 i+1, j}-e_{2 i, j}^{2} \sigma_{2 i, j}\right)+ \\
& \frac{2}{e_{1 i+1 / 2, j}}\left(e_{1+1 / 2, j+1 / 2}^{2} \sigma_{12 i+1 / 2, j+1 / 2}-e_{1 i+1 / 2, j-1 / 2}^{2} \sigma_{12 i+1 / 2, j-1 / 2}\right), \\
& 2 e_{1 i, j+1 / 2} e_{2 i, j+1 / 2} F_{2 i, j+1 / 2}= \\
& e_{1 i, j+1 / 2}\left(\sigma_{1 i, j+1}-\sigma_{1 i, j}\right)-\frac{1}{e_{1 i, j+1 / 2}}\left(e_{1 i, j+1}^{2} \sigma_{2 i, j+1}-e_{1 i, j}^{2} \sigma_{2 i, j}\right)+ \\
& \frac{2}{e_{2 i, j+1 / 2}}\left(e_{2 i+1 / 2, j+1 / 2}^{2} \sigma_{12 i+1 / 2, j+1 / 2}-e_{2 i-1 / 2, j+1 / 2}^{2} \sigma_{12 i-1 / 2, j+1 / 2}\right) .
\end{aligned}
$$

Time stepping of the internal stress tensor on the $\mathrm{C}$ grid is identical to (22) to (24), but with $\sigma_{1}$ and $\sigma_{2}$ calculated on the centre of the grid cells and $\sigma_{12}$ calculated on the corners. The momentum equation is now solved using

$$
\begin{aligned}
& m_{u} \frac{u^{k+1}-u^{k}}{\Delta t}= \\
& F_{1}{ }^{k+1}+A_{u}\left(\tau_{a 1}+c_{D} \rho_{o}\left|\boldsymbol{u}_{o}-\boldsymbol{u}^{k}\right|_{u}\left(u_{o}-u^{k+1}\right)\right)+m_{u} f_{u} v_{u}^{k+c}-m_{u} g \frac{1}{h_{1}} \frac{\partial \eta}{\partial \xi_{1}}, \\
& m_{v} \frac{v^{k+1}-v^{k}}{\Delta t}= \\
& F_{2}{ }^{k+1}+A_{v}\left(\tau_{a 2}+c_{D} \rho_{o}\left|\boldsymbol{u}_{o}-\boldsymbol{u}^{k}\right|_{v}\left(v_{o}-v^{k+1}\right)\right)-m_{v} f_{v} u_{v}^{k+1-c}-m_{v} g \frac{1}{h_{2}} \frac{\partial \eta}{\partial \xi_{2}}
\end{aligned}
$$

where the subscripts $u$ and $v$ represent a variable defined on, or interpolated onto, $u$ and $v$ points, respectively, and where $c$ is alternatively equal to 1 or 0 . On odd iterations, $c=0$ and (34) is solved first. Then, $u^{k+1}$ is interpolated onto $v$ points and is used to solve (35). On even iterations, $c=1$ and (35) is solved first. The updated value of $v$ is then interpolated onto $u$ points to calculate the Coriolis term of (34). This procedure is equivalent to solving the Coriolis term semi-implicitly. Note that, unlike on a B grid, an implicit treatment of 
the Coriolis term on a $\mathrm{C}$ grid would require the simultaneous solution of (34) and (35) all across the domain, which would be computationally expensive.

\subsection{Boundary conditions}

The way in which boundary conditions are dealt with also differs from one grid to another. A no-slip condition is prescribed on land boundaries. On the $\mathrm{B}$ grid, both components of the velocity vector are defined on the coast, and their value is therefore simply set to zero on land points. On the $\mathrm{C}$ grid, in contrast, the normal velocity is defined and set to zero at the coast, but the tangential velocity is not defined. To impose a zero tangential velocity at the coast, a mirror velocity point is defined inland of the boundary, and its value is set to the opposite of the tangential velocity component seaward of the coast, thus delivering a no slip condition on the coast.

On a coarse resolution B grid with a no slip boundary condition, plug flows along lateral boundaries are poorly reproduced. This can adversely affect the transport of sea ice properties if, as it is customary, longshore advective velocities are calculated as the average of the longshore velocity component on the coast, which is zero, and the nearest offshore velocity component. To alleviate this problem, the longshore component of the advective velocity on the $\mathrm{B}$ grid is prescribed to be equal to the nearest offshore velocity component. This boundary condition for advection helps reducing the differences in ice transport and thickness between $\mathrm{B}$ grid and $\mathrm{C}$ grid simulations, and makes integrations carried out on either grid more easily comparable.

\subsection{Linear plastic wave propagation in grids $B$ and $C$}

In ocean modeling, the problem of geostrophic adjustment in finite difference shallow water equations has traditionally provided a useful framework for the intercomparison of discrete staggered grids (Randall, 1994). Interestingly, a parallel analysis can be carried out for the linearized sea ice momentum equations in the case of the cavitating fluid approximation, which consists in setting the parameter $e$ in (8) and (9), or (13) and (14), to infinite, so that sea ice shear stresses vanish (Flato and Hibler, 1992). Assume a motionless sea ice cover of uniform thickness per unit area $h_{0}$ and concentration $A_{0}$. Let us assume that the ice is experiencing compression and that all external forcing is zero. For time scales much larger than the damping time scale for sea ice elastic waves, $T$, the linearized sea ice momentum equations under the 
cavitating fluid approximation are :

$$
\begin{aligned}
m_{0} \boldsymbol{u}_{t}^{\prime} & =-\nabla P^{\prime}-m_{0} f \boldsymbol{k} \times \boldsymbol{u}^{\prime}, \\
P_{t}^{\prime} & =-\left(1+C A_{0}\right) P_{0} \boldsymbol{\nabla} \cdot \boldsymbol{u}^{\prime},
\end{aligned}
$$

where the primed quantities indicate small departures from the unperturbed values and $m_{0}$ and $P_{0}$ are the unperturbed sea ice mass per unit area and compressive sea ice strength, respectively. Equations (36) and (37) are formally equivalent to the shallow water equations linearized about a resting state (Randall, 1994). These equations admit free wave solutions with dispersion relation

$$
\left(\frac{\sigma}{f}\right)^{2}=1+\lambda^{2}\left(k^{2}+l^{2}\right)
$$

where $\sigma$ is the frequency of the wave, $k$ and $l$ are wavenumbers in the $x$ and $y$ directions, respectively (assuming the use of Cartesian coordinates), and $\lambda$ is a deformation radius given by

$$
\lambda=c f^{-1}=\left(\frac{\left(1+C A_{0}\right) P^{*} e^{-C\left(1-A_{0}\right)}}{\rho_{i}}\right)^{\frac{1}{2}} f^{-1},
$$

where $c$ is the phase speed of linear compressive inertia-plastic waves in sea ice and $\rho_{i}$ is the ice density. For a typical central Arctic sea ice concentration in winter of $A_{0}=1$ and values used in our experiments of $P^{*}=20 \times 10^{3} \mathrm{~N}$ $\mathrm{m}^{-2}, C=20$ and $\rho_{i}=900 \mathrm{~kg} \mathrm{~m}^{-3}$, we obtain a phase velocity of plastic waves of $21.6 \mathrm{~cm} \mathrm{~s}^{-1}$ and a deformation radius of about $148 \mathrm{~km}$. A similar analysis for the propagation of uniaxial plastic waves in sea ice has been carried out by Gray (1999).

The numerical equivalent of the dispersion relation (38) for the shallow water equations in different types of Arakawa grids was derived by Arakawa and Lamb and published by Randall (1994). Here we include the expressions for the $\mathrm{B}$ and $\mathrm{C}$ grids, which, assuming a square grid of cell size $d$, are :

$$
\left(\frac{\sigma}{f}\right)^{2}=1+\lambda^{2} \frac{1-\cos (k d) \cos (l d)}{d^{2} / 2}
$$

and

$$
\left(\frac{\sigma}{f}\right)^{2}=\frac{1+\cos (k d)+\cos (l d)+\cos (k d) \cos (l d)}{4}+\lambda^{2} \frac{\sin ^{2}(k d / 2)+\sin ^{2}(l d / 2)}{d^{2} / 4},
$$

respectively. For the LIM applications to be discussed below, the ratio of plastic deformation radius to grid size, $\lambda / d$, lies between 2 and 3. From Fig. 2 , which displays contours of normalised frequency $\sigma / f$ as a function of $k d$ and $l d$ for the case $\lambda / d=2$, it is easy to see that the latter dispersion relation is closer to the exact relation, (38), than the former. In particular, on the $\mathrm{C}$ 
grid, $\sigma$ grows monotonically with $k$ and $l$, and the associated group velocity is always positive, as it is in the continuous case, while, on a B grid, $\sigma$ is not monotonic, and group velocity components are negative whenever $k d$ or $l d$ become larger than $\pi / 2$. Based on these considerations, the performance of the $\mathrm{C}$ grid appears to be superior to that of the B grid at resolutions of $75 \mathrm{~km}$ or less, thus providing additional motivation for using a $\mathrm{C}$ grid sea ice model.

\section{Results and discussion}

All the simulations presented here have used the $2^{\circ}$ global configuration of the model OPA-LIM described by Timmermann et al. (2005), including the forcing. The grid is tripolar, with all three poles located on land, and its minimum resolution is about $65 \mathrm{~km}$ in the Arctic and $50 \mathrm{~km}$ in the Antarctic. Fram Strait is resolved with 5 grid cells, while Bering Strait had to be artificially widened to 2 grid cells. Parry Channel, the strait connecting the Beaufort Sea and Baffin Bay, is represented by a 2 cell-wide passage through the Canadian Archipelago. Wind stress is computed with a drag coefficient of $1.4 \times 10^{-3}$, while ice-ocean drag uses a coefficient of $5.5 \times 10^{-3}$. No turning angle is applied for the calculation of air-ice, air-ocean or ice-ocean stresses. The sea ice strength parameter is $P^{*}=20 \times 10^{3} \mathrm{~N} \mathrm{~m}^{-2}$, and the lead closing parameter $h_{0}=0.3 \mathrm{~m}$.

The ocean model has a time step of $5760 \mathrm{~s}$ (96 minutes), which requires 15 ocean time steps per day, and is coupled to the sea ice model every five time steps. The dynamics time step is $120 \mathrm{~s}$ and the elastic time scale $T$ is 40 times larger to ensure stability. The ocean model is initialized with temperature and salinity fields from the World Ocean Atlas (Levitus, 1982), while the sea ice model initial conditions are set to uniform sea ice thickness of $3 \mathrm{~m}$ in the Arctic and $1 \mathrm{~m}$ in the Antarctic. All experiments started from the same 1948-1959 spin-up integration on a B grid and with VP ice dynamics used by Timmermann et al. (2005), but with $\Delta_{\min }=2 \times 10^{-9} \mathrm{~s}^{-1}$ instead of $2 \times 10^{-8}$ $\mathrm{s}^{-1}$.

The control run was conducted with the EVP formulation of the sea ice dynamics on a $\mathrm{C}$ grid presented in Section 3.2. The results from this experiment do not greatly differ from the validation presented in Timmermann et al. (2005), and so we restrict our analysis to only a few salient features.

The Arctic sea ice extent, defined as the total oceanic area where the ice concentration is greater than, or equal to, $15 \%$, oscillates from about $16 \times$ $10^{6} \mathrm{~km}^{2}$ in March to $10.5 \times 10^{6} \mathrm{~km}^{2}$ in September, in good accordance with observations. In summer, however, ice concentrations remain above $90 \%$ in the central Arctic, and relatively heavy ice covers persist in the Greenland 
and Barents Seas at times when observations show ice-free conditions. Ice thickness varies from more than $6 \mathrm{~m}$ along the Canadian Arctic Archipelago to $4 \mathrm{~m}$ in the central Arctic, and about $2 \mathrm{~m}$ over the western Siberian shelf (Fig. 3 , top panels). A persistent feature of the model is that, compared with the observations of Bourke and Garrett (1987), it tends to somewhat overestimate the ice thickness along the Siberian coast: by about $1 \mathrm{~m}$ in the Kara Sea, 1.5 $\mathrm{m}$ in the Laptev Sea, and $2 \mathrm{~m}$ in the East Siberian Sea.

The two main patterns of the Arctic ice current system, namely the Beaufort gyre and the transpolar ice drift are present (Fig. 3, bottom left panel) but they are weaker than in data produced by the CERSAT from QuikSCAT and SSM/I drift vectors (Ezraty and Piollé, 2004). For the comparison, we interpolate monthly drift vectors from a $62.5 \mathrm{~km}$ polar stereographic grid to our simulation grid and we average data over all winter seasons (October to April) from 1992 to 2001 (Fig. 3, bottom right panel). Simulated velocities along the Alaskan North Coast in winter are about $0-2 \mathrm{~cm} \mathrm{~s}^{-1}$ instead of $1-5 \mathrm{~cm} \mathrm{~s}^{-1}$ in observations, and the maximum is located nearer to Bering Strait. The simulated transpolar drift is also weaker, $1-3 \mathrm{~cm} \mathrm{~s}^{-1}$ instead of $2-4 \mathrm{~cm} \mathrm{~s}^{-1}$, and its location is influenced by the absence of the Franz Joseph Archipelago in our configuration. This weaker drift is partly due to the small ratio between the atmospheric drag coefficient $\left(1.4 \times 10^{-3}\right)$ and the ice-ocean drag coefficient $\left(5.5 \times 10^{-3}\right)$.

Following Martin and Gerdes (2007), we have computed histograms of monthly mean ice drift speed in the central Arctic basin to characterise the ice motion. For this calculation, the region of interest is the area located north of $70^{\circ}$ $\mathrm{N}$ between $50^{\circ} \mathrm{E}$ and $270^{\circ} \mathrm{E}$, and north of $80^{\circ} \mathrm{N}$ between $270^{\circ} \mathrm{E}$ and $50^{\circ}$ E, as shown on the third panel of Fig. 3. The left panel of Fig. 4 shows histograms for March and September, both of which compare rather well with the observational estimates used by Martin and Gerdes (2007). A mode at very low speed exists for both months. In March, sea ice speeds are mainly below $0.05 \mathrm{~m} \mathrm{~s}^{-1}$, and $45 \%$ of them are actually smaller than $0.01 \mathrm{~m}^{-1} s$. In September, ice tends to be faster but, still, it almost nowhere reaches $0.10 \mathrm{~m}$ $\mathrm{s}^{-1}$. While these results are encouraging, a more detailed analysis should be conducted to ascertain the role that anomalous features of the ice distribution, such as the excess thickness along the Eurasian coast, play in modifying the flow of sea ice. The mean ice export through Fram Strait is about $0.11 \mathrm{~Sv}$, in the upper limit of observational estimates.

In the Southern Ocean, the ice extent oscillates between $5 \times 10^{6} \mathrm{~km}^{2}$ in February and $19 \times 10^{6} \mathrm{~km}^{2}$ in August, values which are close to the observational ones. Sea ice concentrations are also quite realistic, except along coastlines, where polynya formation cannot be appropriately represented because of the coarse resolution of the model (Fig. 5, top panels). The winter mean ice velocity field for the period 1979-1997 (March to November) shows a fairly strong 
westward drift of $2-8 \mathrm{~cm} \mathrm{~s}^{-1}$ all around Antarctica, and an offshore eastward drift of about $2-6 \mathrm{~cm} \mathrm{~s}^{-1}$ (Fig. 5, bottom left panel). This is similar to the circulation obtained by averaging SSM/I monthly mean ice drift from the Atlas of Antarctic Sea Ice Drift (Schmitt et al., 2004) over the same period (Fig. 5, bottom right panel). Observation vectors have been interpolated on the simulation grid for comparison. The Weddell, Ross and Kerguelen gyres, with drift speeds of $2-5 \mathrm{~cm} \mathrm{~s}^{-1}$, are all represented by the model, although the observed northward ice drifts in the Weddell and Ross regions are wider and somewhat stronger than in our simulation, presumably at least partly because of deficiencies in the surface wind stress. The histogram of velocities for the entire Southern Ocean reveals a sea ice cover that is significantly faster than its central Arctic counterpart. However, the ice speed mode is still in the vicinity of $0.01 \mathrm{~m} \mathrm{~s}^{-1}$ all year round.

The results of the EVP simulation on a $\mathrm{C}$ grid are quite encouraging. However, before adopting this formulation as standard, it is important to compare those results with output from integrations that use other discretization methods, as discussed in Section 3. To this end, we have conducted a number of 5-year experiments starting in 1960. These experiments are as follows. Experiment EVPB1 uses the EVP discretization of Hunke and Dukowicz (2002) on a B grid. Experiment EVPB2 is as EVPB1, but with the simpler, centred difference discretization outlined in Section 3.1. The third experiment, EVPC1, uses the centred difference, C-grid formulation of Section 3.2, the same as in the control run. A second C grid experiment, denoted EVPC2, was performed in which all straits and passages with a width of only one grid point were closed to ice advection. Finally, three experiments were also carried out using the VP, B-grid discretization of Fichefet and Morales Maqueda (1997), and these are all collectively referred to as VPB experiments. The first VP experiment (VPB1) uses $\Delta_{\text {min }}=2 \times 10^{-9} \mathrm{~s}^{-1}$ and 1 subcycling time step, as in the spinup integration. The second experiment (VPB2) is like the first, but using 3 subcycling time steps. The third experiment (VPB3) uses $\Delta_{\min }=2 \times 10^{-8} \mathrm{~s}^{-1}$ and 3 subcycling time steps. The impact of the different methods of solution of the sea ice dynamics on the Southern Ocean ice cover are minuscule, and so we will concentrate on results for the Northern Hemisphere.

We start by examining the ability of the VP discretization, as implemented in Fichefet and Morales Maqueda (1997), to approximate a plastic flow. For numerical convergence reasons, the VP dynamics of Fichefet and Morales Maqueda (1997) required the use of a relatively large value of $\Delta_{\text {min }}$, namely, $2 \times 10^{-8} \mathrm{~s}^{-1}$. This figure is probably an order of magnitude too large for a limiting deformation rate, and leads to an excessively viscous ice dynamics. In contrast, the EVP dynamics work well with arbitrarily small values of $\Delta_{\min }$, as states with small deformation rates can be gently achieved through progressive elastic relaxation. To evaluate the impact of a relatively high value of $\Delta_{\min }$ on sea ice simulations with the VP rheology, we carried out three experiments. They dif- 
fer in the minimum value of $\Delta_{\text {min }}$ used and also in the number of subcycling time steps for the dynamics (subcycling consists in solving the momentum equation with a time step smaller than the one used for ice thermodynamics and transport).

To see how well the elliptic relation between principal stress components is fulfilled, we compute the quadratic function $\left(\sigma_{1} / P+1\right)^{2}+e^{2}\left(\sigma_{s} / P\right)^{2}$ from (11) and check how close it is to 1 . A greater value corresponds to a state out of the elliptic yield curve, while a smaller value indicates a state inside the ellipse. With one subcycling time step, the VP formulation does a very poor job at representing the yield curve. In the example shown in the left panel of Fig. 6, we can see large regions of the Arctic are in a stress state located outside the ellipse. Ellipticity is partly recovered when 3 subcycling time steps are applied (central panel of Fig. 6), but there are still situations when the quadratic expression on the left hand side of (11) is greater than 1. Using 3 subcycling time steps and a higher value of $\Delta_{\min }$ further improves the representation of the elliptical yield curve thanks to a better convergence of the numerical scheme, but it generates more creep flow, where the value of quadratic function is lower than 1, as shown in the right panel of Fig. 6. More elaborated implicit schemes can be used to improve the convergence while using small values of $\Delta_{\min }$ (Zhang and Hibler, 1997; Zhang and Rothrock, 2000).

In terms of the representation of the Arctic winter mean (December to March) ice thickness geographical distribution, the impact of using 3 subcycling times steps (VPB2) instead of just 1 (VPB1) is a diminution of more than 0.15 $\mathrm{m}$ along the Canadian Arctic Archipelago, in the central Beaufort Sea and in the Laptev Sea (Fig. 7, left panel). In contrast, there is more ice along the eastern coast of Greenland. Differences are even more marked between experiments VPB3 and VPB2, which differ by the magnitude of $\Delta_{\min }$ (Fig. 7 , right panel). There is a sensible decrease in both the horizontal gradients and spatial mean value of the ice thickness across the entire central Arctic basin in VPB3 compared to VPB2. Ice is $~ 10 \%$ thinner in the central Arctic and $\sim 10 \%$ thicker in the Greenland and northern Barents seas. This is so because the more viscous dynamics of VPB3 allows for a winter flow in the central Arctic that is 5-10\% stronger than in VPB2, and causes as well an easier transport of ice across Fram Strait and Parry Channel.

The differences between the results of the three VPB experiments illustrate the importance of guaranteeing that plastic ice flow is well represented. This requires the use of relatively small values of $\Delta_{\min }$ in the VP dynamics, which results in a fairly slow numerical convergence toward the plastic solution. In contrast, sensitivity tests with the EVP rheology show that a small value of $\Delta_{\min }\left(2 \times 10^{-12} \mathrm{~s}^{-1}\right.$, say $)$ can be used without in any way compromising convergence. The EVP solution is also not affected by the particular value 
of $T$ chosen, as long as it is several times smaller than the thermodynamics and transport time steps. Thus, with suitable $\Delta_{\min }$ and $T$ values, ice internal stress states calculated with the EVP formulation tend to be much closer to the elliptical yield curve than those determined using the VP rheology.

The aim of experiments EVPB1, EVPB2, EVPC1 and EVPC2 was to examine the influence of the spatial discretization on EVP solutions. Overall, there is a reassuring similarity between the results of all four experiments, although we note that the $\mathrm{B}$ grid tends to develop checkerboard patterns in certain variables, such as the ice divergence field. In most cases, this computational mode does not appear to have a direct impact on the ice dynamics, but it could be a problem if deformation rates are used in the calculation of the ice thickness redistribution. The use of a bilinear approach à la Hunke and Dukowicz (2002), rather than the more simple centred difference formulation we have proposed in Section 3.1, helps attenuating the checkerboard mode thanks to the spatial averaging involved in the calculation of the internal stress force. This numerical mode cannot appear on a $\mathrm{C}$ grid.

An example of instantaneous shearing strain rates is shown in Fig. 8 for the EVPB1, EVPB2 and EVPC2 simulations. The shearing strain rate patterns look similar in all three experiments and show how the EVP dynamics is capable of creating spatial linear and relatively narrow features along which high ice deformation occurs. This linear features act as divides between regions where the ice motion is nearly rigid. Looking into these features more closely, we note that their detailed structure depends both on the discretization and on the relative orientation of linear features and the numerical grid. The B grid with the simple EVP discretization (EVPB2) produces the narrowest features (just two cells wide) when they are aligned with the grid. However, as it might have been expected, checkerboard patterns in shear stain rates are very prominent in this discretization, while they are less so in the cases EVPB1 and EVPC2. Nevertheless, these differences do not seem to influence the ice drift very much. Ice drift patterns are fairly similar in all simulations.

Winter mean sea ice thickness differences between EVPB1 and EVPB2 are fairly small except in the Lincoln Sea and along Parry Channel (Fig. 9, right panel). These very localized differences do not seem to have a significant largescale impact, and so we have not investigated their origin in any great detail. The ice volume export through Fram Strait is virtually the same in both experiments: about $0.11 \mathrm{~Sv}$, with a standard deviation of $0.08 \mathrm{~Sv}$.

Of perhaps greater interest are the differences between the $\mathrm{B}$ grid and $\mathrm{C}$ grid integrations. The left panel of Fig. 10 shows the difference in winter mean ice thickness between experiments EVPC1 and EVPB1. Ice in the central Arctic tends to be thinner in the EVPC1 experiment, with the exception of a few choke points, such as Parry Channel and the passages between Eurasia and the 
New Siberian Islands, Severnaya Zemlya and Novaya Zemlya. These passages are represented with just one grid point in our model, and, therefore, no ice can flow through them when a B grid is used. As a result, ice simulated in EVPB1 tends to accumulate on the upstream side of these passages and, thus, be thicker than it would be on a $\mathrm{C}$ grid, while, downstream of the passages, the ice tends to be generally thinner. This is confirmed by the results of a second C grid experiment, EVPC2, in which all one cell straits were closed to ice transport. The right panel of Fig. 10 shows that the differences in winter sea ice thickness between this experiment and EVPB1 have sensibly decreased on both sides of the narrow central Arctic passages. In both EVPC1 and EVPC2, ice area and volume exports across Fram Strait are about 5\% smaller than in EVPB1. In contrast, ice circulation in the Beaufort Gyre is slightly stronger $(+5 \%)$, and southward velocities along the east Greenland coast are around $10 \%$ larger, which is consistent with the existence of the band of thicker ice one can observe all along the eastern Greenland coast, and that counters the larger onshore component of the Coriolis force associated with the 10\% higher velocities.

\section{Conclusions}

The elastic-viscous-plastic (EVP) sea ice rheology formulation of Hunke and Dukowicz (2002) has been incorporated in the Louvain-la-Neuve sea-Ice Model, version 2 (LIM2), which has until now used a viscous-plastic (VP) sea ice dynamics (Hibler, 1979). Two centred difference discretizations of the EVP rheology have also been introduced, one defined on a $\mathrm{B}$ grid and the second defined on a $\mathrm{C}$ grid. These centred difference formulations help reducing computation costs for the sea ice dynamics by about a factor of 2 compared to the more sophisticated approach of Hunke and Dukowicz (2002).

Because LIM runs normally coupled to a $\mathrm{C}$ grid ocean model (the Nucleus for European Modelling of the Ocean, NEMO), we have retained the centred difference $\mathrm{C}$ grid formulation of the EVP dynamics as the most suitable for LIM. The performance of the coupled ice-ocean model has been illustrated with results from a long simulation spanning the years 1960 to 2001. The model reproduces well the sea ice concentration, thickness and velocity fields in both hemispheres.

We have conducted a number of short experiments to test the sensitivity of the model to the use of the different implementations of the ice rheology. We have first compared the performance of the original VP formulation in LIM with the new EVP implementation. Attaining appropriate plastic behavior with the VP dynamics requires the use of subcycling and a fairly small value of $\Delta_{\min }$ (on the order of $2 \times 10^{-9} \mathrm{~s}^{-1}$ or less), which hinders convergence of 
the relaxation algorithm used by the VP method. In contrast, computing time is not affected by the value of $\Delta_{\min }$ when using the EVP formulation.

We have also intercompared EVP simulations with different spatial discretizations. The two B grid discretizations we have investigated, namely, the one by Hunke and Dukowicz (2002) and the simplified discretization described in Section 3.1, lead both to very similar results, at least for relatively coarse spatial model resolutions. Disparities in ice thickness between the centred difference formulations on B grid and C grid are largely associated with slower ice transport through narrow straits and along coastlines on the $\mathrm{B}$ grid. There is also a tendency for the $\mathrm{C}$ grid formulation to produce slightly higher ice velocities in the central Arctic, but also a reduced ice export through Fram Strait.

In summary, the new EVP formulation on a $\mathrm{C}$ grid implemented in LIM is able to produce realistic ice fields in both hemispheres. In addition, the EVP ice dynamics approaches plasticity better and numerically more efficiently than the previous VP implementation. We therefore recommend the use of the $\mathrm{C}$ grid EVP formulation of the ice dynamics in future LIM applications.

\section{Acknowledgements}

We are grateful to Martin Vancoppenolle, Anne de Montety and Olivier Lietaer for helpful comments. The present study was carried out within the scope of the project "A second-generation model of the ocean system", which is funded by the Communaute Francaise de Belgique, as Actions de Recherche Concertées, under contract ARC 04/09-316 (http://www.climate.be/SLIM). This work has also been partly funded by the United Kingdom's Natural Environment Research Council through its Core Research Programme Oceans 2025 and by the Belgian Federal Science Policy Office. 


\section{References}

Bourke, R. H. and R. P. Garrett (1987) Sea ice thickness distribution in the Arctic Ocean. Cold Regions Science and Technology, 13, pp.259-280.

Connolley, W. M., J. M. Gregory, E. Hunke and A. J. McLaren (2004) On the consistent scaling of terms in the sea-ice dynamics equation. Journal of Physical Oceanography, 34(7), pp.1776-1780.

Driesschaert, E., T. Fichefet, H. Goosse, P. Huybrechts, I. Janssens, A. Mouchet, G. Munhoven, V. Brovkin, and S.L. Weber (2007) Modeling the influence of Greenland ice sheet melting on the Atlantic meridional overturning circulation. Geophysical Research Letters, 34, L10707, doi:10.1029/2007GL029516.

Ezraty, R. and J.F. Piollé (2004) Sea-ice drift in the central Arctic combining QuikSCAT and SSM/I sea ice drift data - User's manual (v1.0, April 2004) Available at ftp://ftp.ifremer.fr/ifremer/cersat/products/gridded/psidrift/documentation/merged.pdf

Fichefet, T. and M. A. Morales Maqueda (1997) Sensitivity of a global sea ice model to the treatment of ice thermodynamics and dynamics. Journal of Geophysical Research, 102, pp.12609-12646.

Fichefet, T. and M. A. Morales Maqueda (1999) Modelling the influence of snow accumulation and snow-ice formation on the seasonal cycle of the antarctic sea-ice cover. Climate Dynamics, 15, pp.251-268.

Flato, G. M. and W. D. Hibler (1992) Modeling pack ice as a cavitating fluid. Journal of Physical Oceanography, 22, pp.626-651.

Goosse, H. (1997) Modelling the large-scale behaviour of the coupled oceansea ice system. Ph. D. thesis, 231 pp., Fac. des Sci. Appl. Univ. Cath. de Louvain, Louvain-la-Neuve, Belgium.

Goosse, H. and T. Fichefet (1999) Importance of ice-ocean interactions for the global ocean circulation: A model study. Journal of Geophysical Research, 104, pp.23337-23355.

Gray, J. M. N. T. (1999) Loss of hyperbolocity and ill-posedness of the viscousplastic sea ice rheology in uniaxial divergent flow. Journal of Physical Oceanography, 29(11), pp.2920-2929.

Hibler, W. D. III (1979) A dynamic thermodynamic sea ice model. Journal of Physical Oceanography, 9, pp.817-846.

Hofmann, M. and M. A. Morales Maqueda (2006) Performance of a secondorder moment advection scheme in an ocean general circulation model. Journal of Geophysical Research, 111, pp.C05006, doi:10.1029/2005JC003279.

Hunke, E. C. and J. K. Dukowicz (1997) An elastic-viscous-plastic model for sea ice dynamics. Journal of Physical Oceanography, 27, pp.1849-1867.

Hunke, E. C. and J. K. Dukowicz (2002) The elastic-viscous-plastic sea ice dynamics model in general orthogonal curvilinear coordinates on a sphereincorporation of metric terms. Monthly Weather Review, 130, pp.1848-1865.

Hunke, E. C. and W. H. Lipscomb (2006) CICE: the Los Alamos Sea Ice Model Documentation and Software User's Manual, Tech. Report LA-CC- 
98-16, 59 pp., T-3 Fluid Dynamics Group, Los Alamos National Laboratory, Los Alamos NM 87545.

Hunke, E. C. and Y. Zhang (1999) A Comparison of sea ice dynamics models at high resolution Monthly Weather Review, 127, pp.396-408.

Kantha, L. H. and C. A. Clayson (2000) Numerical Models of Oceans and Oceanic Processes. Academic Press, ISBN 012 4340687, 940 pp.

Leppäranta, M. (2005) The Drift of Sea Ice. Springer, Helsinki, 266pp.

Levitus, S. (1982) Climatological atlas of the world ocean. NOAA Professional Paper 13, US Government Printing Office, Washington DC.

Madec, G., P. Delecluse, M. Imbard and C. Lvy (1999) OPA 8.1, Ocean general circulation model reference manual. Laboratoire d'Ocanographie Dynamique et de Climatologie, Paris, France.

Marti O., P. Braconnot, J.-L. Dufresne, J. Bellier, R. Benshila, S. Bony, P. Brockmann, P. Cadule, A. Caubel, F. Codron, N. de Noblet, S. Denvil, L. Fairhead, T. Fichefet, M.-A. Foujols, P. Friedlingstein, H. Goosse, J.-Y. Grandpeix, E. Guilyardi, F. Hourdin, G. Krinner, C. Lvy, G. Madec, J. Mignot, I. Musat, D. Swingedouw, and C. Talandier (2008) Key features of the IPSL ocean atmosphere model and its sensitivity to atmospheric resolution. Climate Dynamics, submitted.

Martin, T. and R. Gerdes (2007) Sea ice drift variability in Arctic Ocean Model Intercomparison Project models and observations. Journal of Geophysical Research, 112, pp.C04S10, doi:10.1029/2006JC003617.

McPhee, M. G. (1992) Turbulent heat fluxes in the upper ocean under sea ice. Journal of Geophysical Research, 97, pp.5365-5379.

Montoya, M., A. Griesel, A. Levermann, J. Mignot, M. Hofmann, A. Ganopolski and S. Rahmstorf (2005) The earth system model of intermediate complexity CLIMBER-3 $\alpha$. Part I: description and performance for present-day conditions. Climate Dynamics, 26, pp.237-263.

Randall, D. A. (1994) Geostrophic adjustment and the finite-difference shallow-water equations. Monthly Weather Review, 122, pp.1371-1377.

Randall, D. A., R.A. Wood, S. Bony, R. Colman, T. Fichefet, J. Fyfe, V. Kattsov, A. Pitman, J. Shukla, J. Srinivasan, R.J. Stouffer, A. Sumi and K.E. Taylor (2007) Climate Models and Their Evaluation. In: Climate Change 2007: The Physical Science Basis. Contribution of Working Group I to the Fourth Assessment Report of the Intergovernmental Panel on Climate Change [Solomon, S., D. Qin, M. Manning, Z. Chen, M. Marquis, K.B. Averyt, M.Tignor and H.L. Miller (eds.)]. Cambridge University Press, Cambridge, United Kingdom and New York, NY, USA.

Schmitt, C., Ch. Kottmeier, S. Wassermann and M. Drinkwater (2004) Atlas of Antarctic Sea Ice Drift. Available at http://www.imk.unikarlsruhe.de/seaiceatlas

Timmermann, R., H. Goosse, G. Madec, T. Fichefet, C. Ethe, and V. Dulire (2005) On the representation of high latitude processes in the orca-lim global coupled sea ice-ocean model. Ocean Modelling, 8, pp.175-201.

Vancoppenolle, M., T. Fichefet, H. Goosse, S. Bouillon, G. Madec and M. 
A. Morales Maqueda (2008) Simulating the mass balance and salinity of Arctic and Antarctic sea ice. 1. Model description and validation. Ocean Modelling, doi:10.1016/j.ocemod.2008.11.003, Article in Press.

Zhang, J. and W. D. III Hibler (1997) On an efficient numerical method for modeling sea ice dynamics. Journal of Geophysical Research, 102, pp.86918702.

Zhang, J. and D. A. Rothrock (2000) Modeling Arctic sea ice with an efficient plastic solution. Journal of Geophysical Research, 105, pp.3325-3338. 


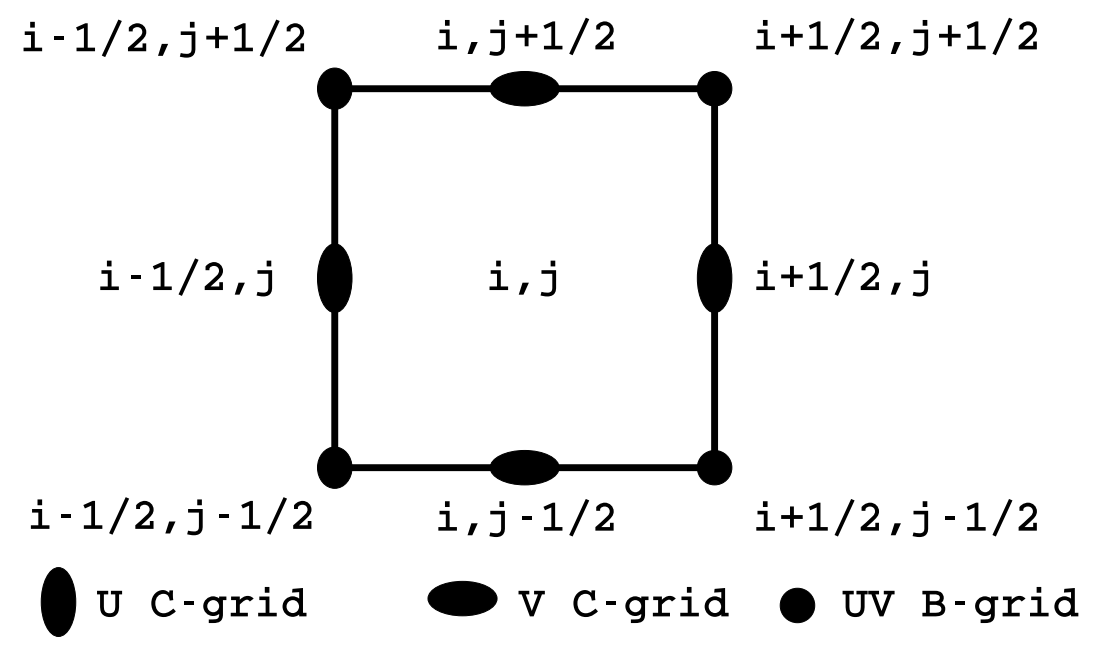

Fig. 1. Centred difference grid showing the indexing convention utilised in the paper.
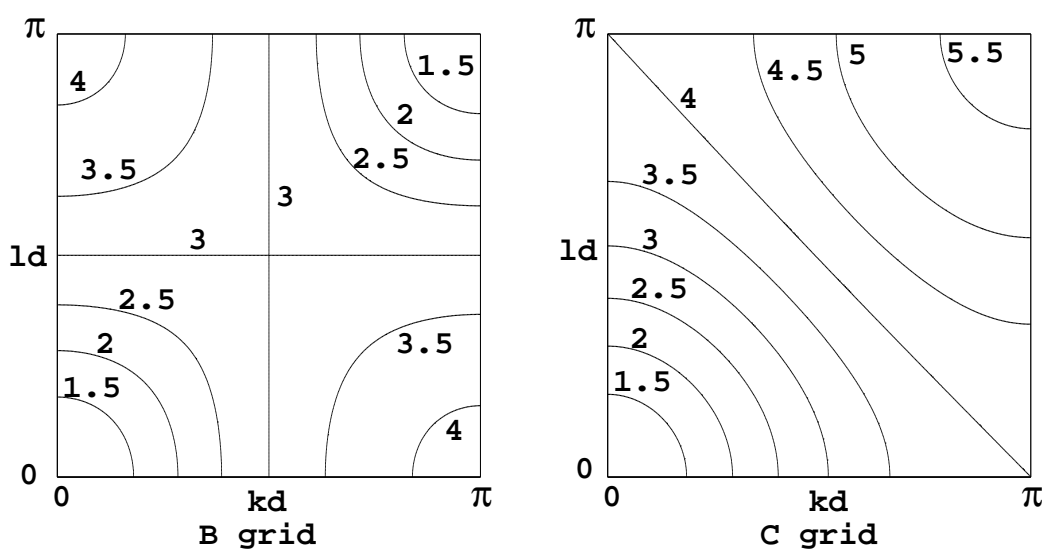

Fig. 2. Contours of normalised frequency $\sigma / f$ as a function of $k d$ and $l d$ from equations 40 (left) and 41 (right) with $\lambda / d=2$. 


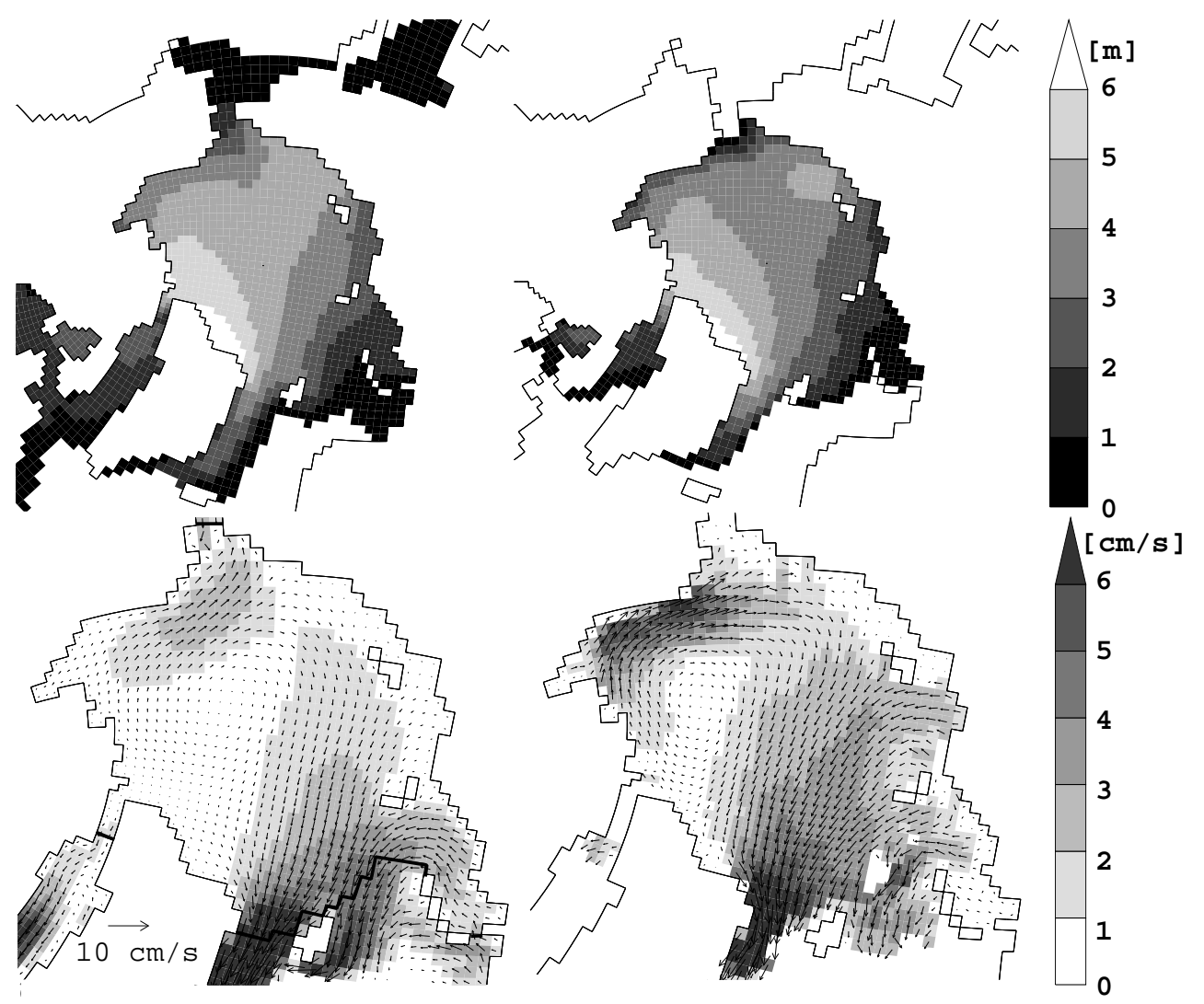

Fig. 3. Simulated Arctic mean sea ice thicknesses in March (top left) and September (top right) for the period 1965-2001 and winter mean sea ice velocities (October to April) for the period 1992-2001 simulated by the model (bottom left) and from observations (bottom right). The black line in the third panel bounds the region used to calculate velocities distributions.
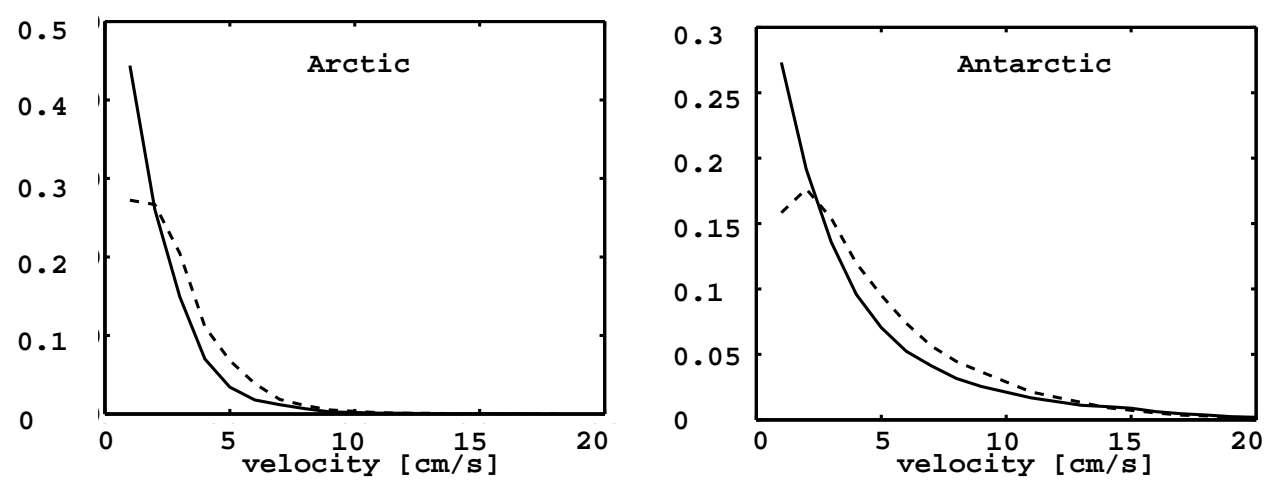

Fig. 4. Left: Histogram of monthly mean ice velocities in the central Arctic (as delimited by the black line shown in the third panel of Fig. 3). Solid line for March and discontinuous line for September. Right: Histogram of monthly mean velocities in the Southern Ocean. Solid line for September and discontinuous line for March. Drift speeds below $0.5 \mathrm{~cm} \mathrm{~s}^{-1}$ have not been taken into account. The bin width is $1 \mathrm{~cm} \mathrm{~s}^{-1}$, beginning at $0.5 \mathrm{~cm} \mathrm{~s}^{-1}$. The period of interest is 1965-2001. 


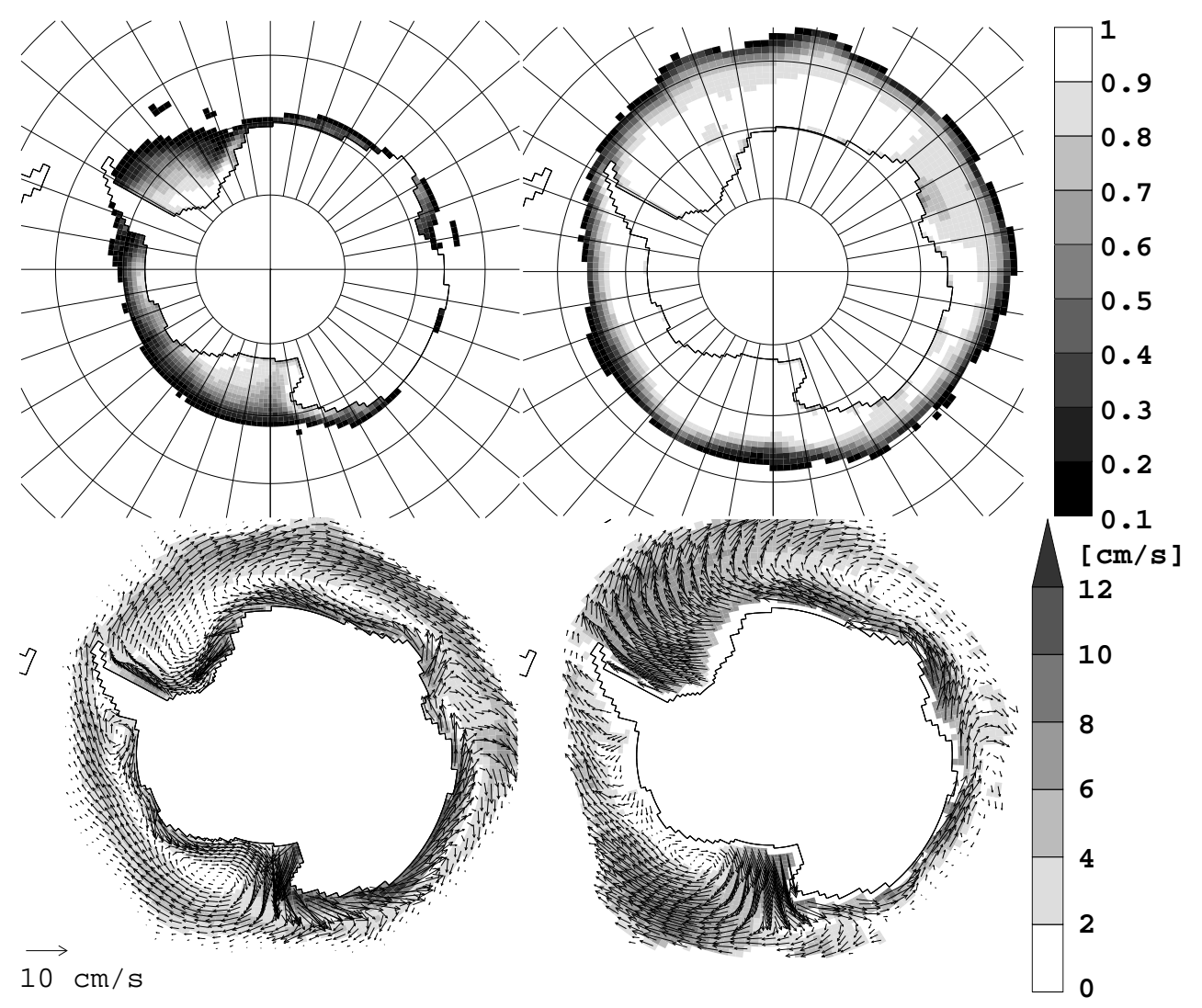

Fig. 5. Simulated Southern Ocean mean sea ice concentration in March (top left) and September (top right) for the period 1965-2001 and winter mean sea ice velocities (March to November) for the period 1979-1997 simulated by the model (bottom left) and from observations (bottom right).

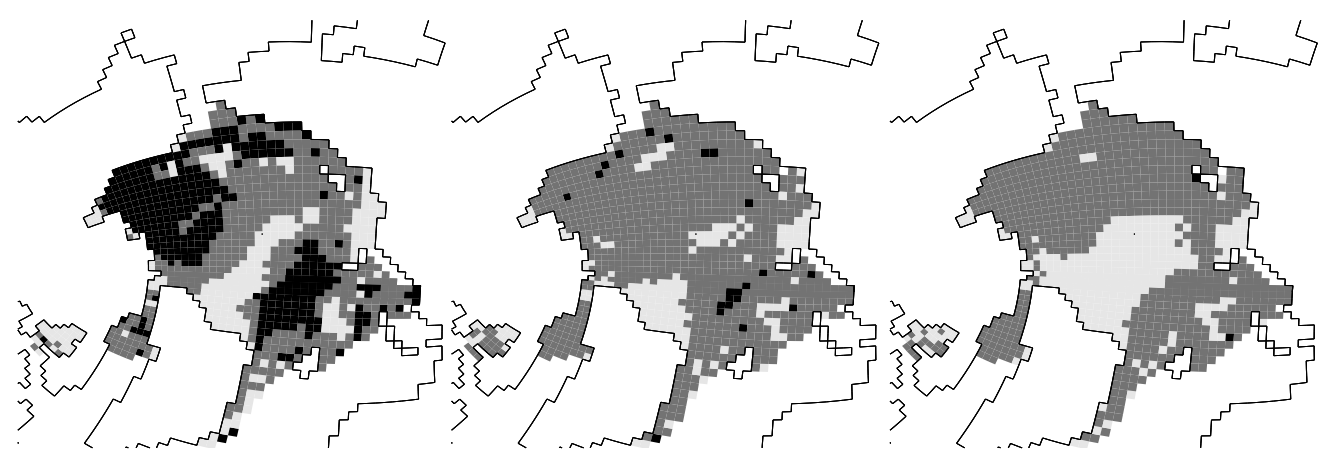

Fig. 6. Left hand side of (11) calculated from instantaneous stress states on a simulation day of September 1964 in experiments VPB1 (left), VPB2 (centre) and VPB3 (right). Values larger than 1.2 (black) correspond to states located out of the ellipse, values between 0.8 and 1.2 (grey) correspond to states near the ellipse and values smaller than 0.8 (light grey) correspond to states inside the ellipse. 

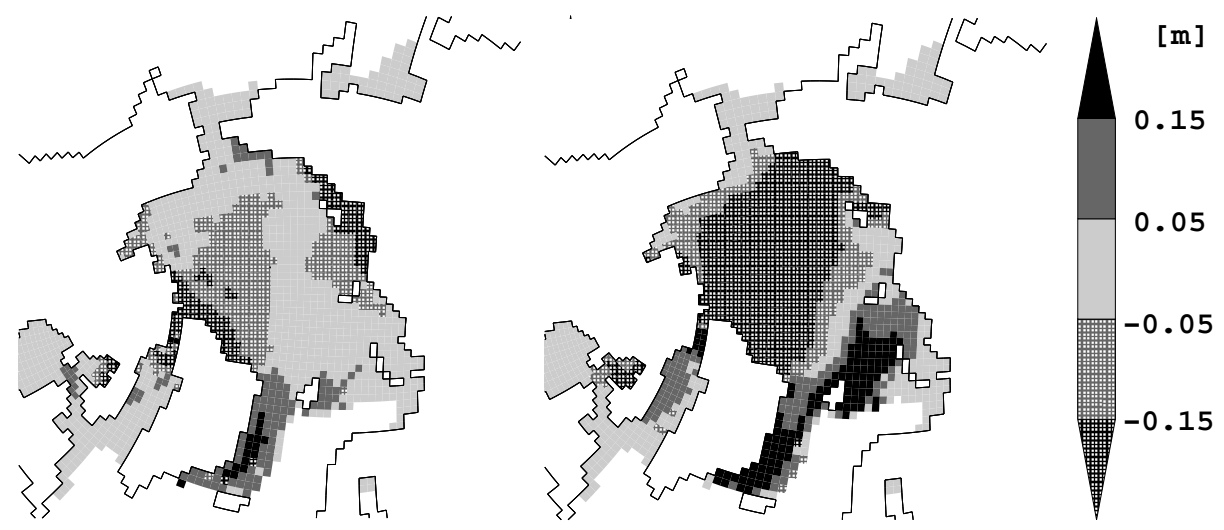

Fig. 7. Mean ice thickness differences between experiments VPB2 and VPB1 (left) and between experiments VPB3 and VPB2 (right) in winter (October to December average for 1963 and 1964).

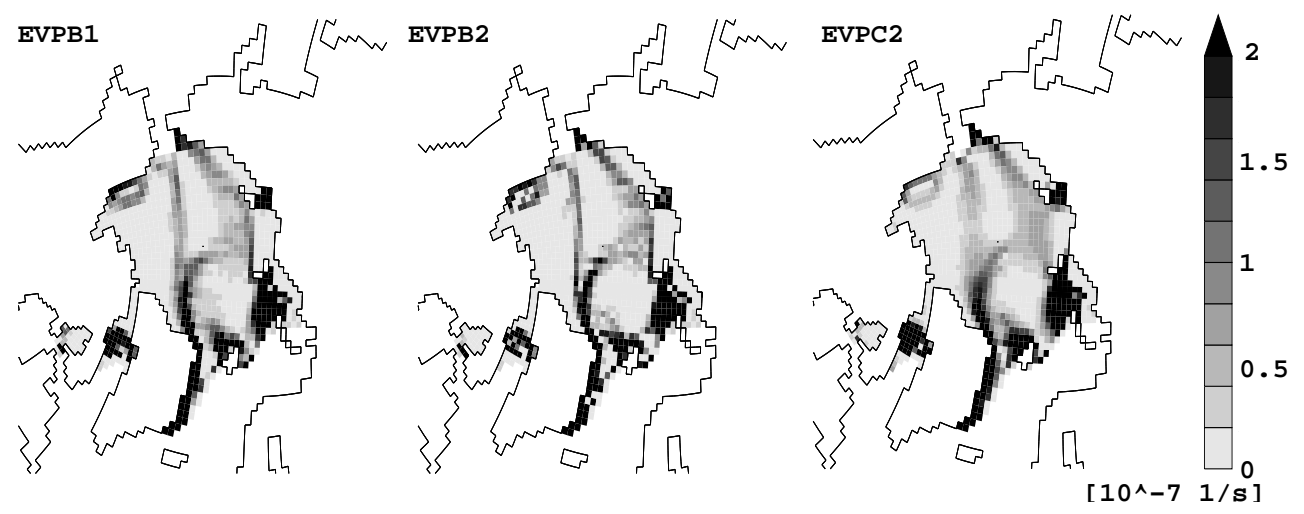

Fig. 8. Instantaneous shearing strain rates in a simulation day of October 1964 with experiments EVPB1 (left), EVPB2 (centre) and EVPC2 (right).
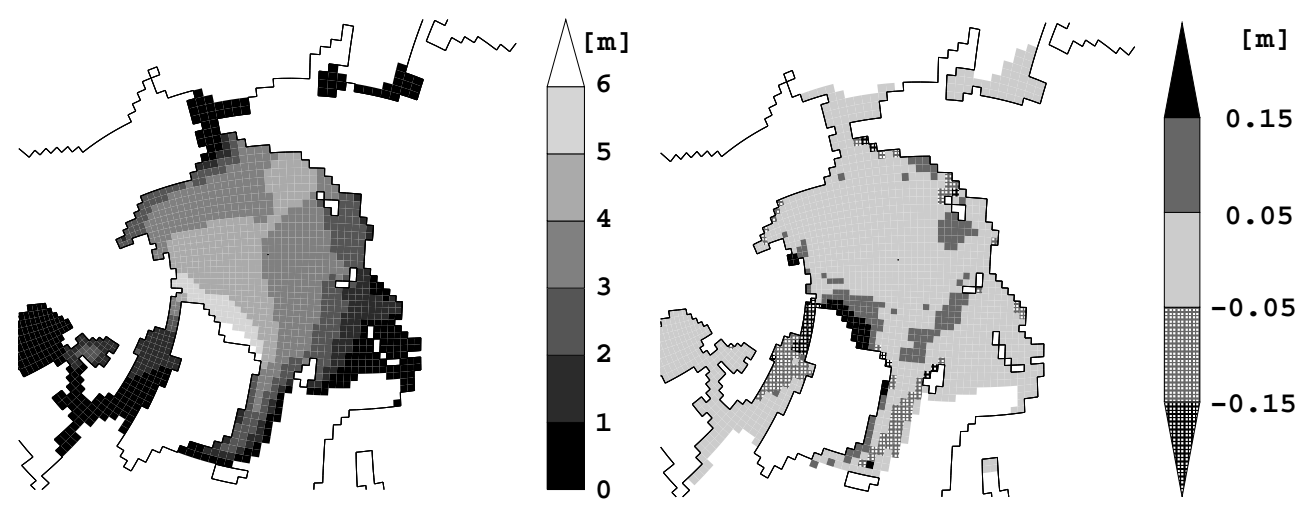

Fig. 9. Mean ice thicknesses in experiment EVPB1 (left) and mean ice thickness differences between experiments EVPB2 and EVPB1 (right) in winter (October to December average for 1963 and 1964). 

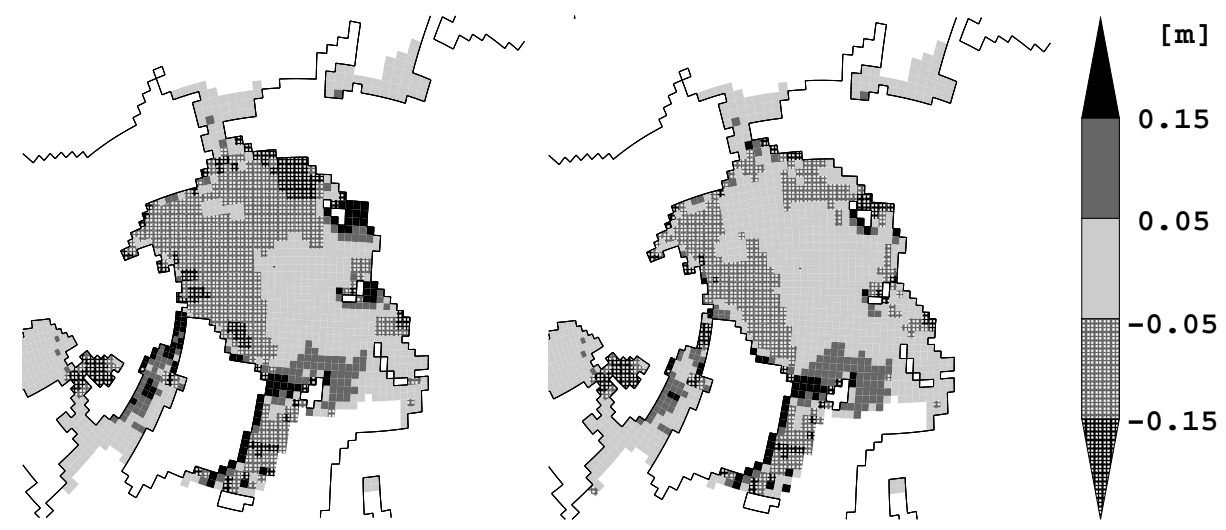

Fig. 10. Mean ice thickness differences between experiments EVPC1 and EVPB1 (left) and between experiments EVPC2 and EVPB1 (right) in winter (October to December average for 1963 and 1964). 